\title{
Climatic droplet keratopathy, exfoliation syndrome, and cataract
}

\author{
S Resnikoff, G Filliard, B Dell'Aquila
}

\begin{abstract}
During a countrywide survey we assessed the prevalence of climatic droplet keratopathy (CDK) in a randomised sample of 2446 subjects representative of the population of the Republic of Diibouti. The investigation of the relationship between CDK and two diseases considered to be related to exposure to ultraviolet light - namely, exfoliation syndrome and cataract - was planned as a case control study. In the rural area prevalence of $\mathrm{CDK}$ was five times higher than in the urban one $(2.8 \%$ vs $0.5 \%$ ) and varied according to districts. The highest rates were observed where the inhabitants' activities were related to the sea. The case control study revealed that the opacification of the lens was about three times commoner in patients with CDK than in patients without CDK $(p=0.03)$ and that the exfoliation syndrome was about six times commoner in patients with CDK than in controls of similar age, sex, climatic conditions, and lens status $(p=0.02)$. Moreover, we noticed that the sequelae of corneal perforations were about 30 times commoner in patients with CDK than in controls of similar age $(\mathbf{p}<0.00001)$.
\end{abstract}

Climatic droplet keratopathy $(\mathrm{CDK})$ is a corneal degeneration characterised by an opacification at the level of the Bowman's membrane. The earliest change to be seen is a fine collection of translucent droplets in the temporal and nasal aspects of the cornea within the area of the palpebral fissure. In more severe cases this droplet formation proceeds to cover the pupillary axis. Rarely, in the most severe cases, larger, golden droplets occur, a condition also known as 'spheroidal droplet degeneration'.

Since previous studies have shown that CDK might be linked to lens anomalies ${ }^{1-3}$ we set ourselves two objectives: to assess the prevalence of $\mathrm{CDK}$ in a population based survey; and to study the relationships between CDK and other eye diseases considered to be related to ultraviolet light exposure, namely exfoliation syndrome and cataract.

OCCGE - Institut d'Ophtalmogie Tropicale de l'Afrique (Institute of African Tropical Ophthalmology), BP 248, Bamako, Mali $S$ Resnikoff G Filliard B Dell'Aquila Correspondence to: Correspondence to:
S Resnikoff, IOTA, BP 248 Bamako, Mali. Bamako, Mali. 10 May 1991

\section{Subjects and methods}

The study was carried out on a representative sample of the Djiboutian population. The Republic of Djibouti is a country with an area of $23200 \mathrm{~km}^{2}$, situated in the horn of Eastern Africa. It has an estimated population of 470000 . Some $75 \%$ of the population live in urban areas, particularly in the city of Djibouti. The other $25 \%$ are basically nomadic in the semidesert hinterland and extend across the borders into
Somalia and Ethiopa. The average annual rainfall is less than $125 \mathrm{~mm}$. Life expectancy at birth was estimated to be 45 years in 1985 with an infant mortality rate of $200 / 1000$ live births.

We used a two stage random cluster sampling ${ }^{45}$ with two strata (rural and urban). The sampling frame consisted of the 1985 census. From a random start 65 sites ('clusters') were selected: 35 in the rural area and 30 in the urban one. Within each site we selected at random a starting point ('household'). Examination of all individuals began in the starting household and then continued to the next nearest one, until a total of 35 people had been examined. All individuals living in the last household falling into the sample were included even if the number was over 35 .

In accordance with this methodology 2446 people were selected: 1117 in the urban sector (one inhabitant per 200) and 1329 in the rural one (one inhabitant per 50), making up a representative sample of the Djiboutian population.

The prevalence was determined on these two samples. To take into account the differences in age distribution we used a computational process known as standardisation (age and sex adjustment on WHO's African standard population).

The investigation of the relationship between CDK and cataract, or exfoliation syndrome, was planned as a case control study. The cases were all patients with CDK found during the survey; the controls were all adults aged 40 and above, taken from the samples. Aphakic patients were excluded from the case control study.

Confounding variables were neutralised in two ways: first, by Mantel-Haenszel's method. Age stratification was by 10 year age classes. Using narrower classes would not have been reasonable because of the absence of registration and the approximate nature of the patients' knowledge of their ages. Secondly, by matching on age, sex, and neighbourhood. Two controls were selected for each case according to the following method: same sex, same district, same age, or failing that (three cases) same age plus or minus five years. Whenever several individuals met these criteria, the two controls were randomly selected.

All ocular examinations were carried out by an ophthalmologist with a portable slit-lamp (Kowa SL5). The pupils of each person of 40 and above were dilated with one drop of tropicamide. When dilatation was inadequate this was repeated, and occasionally one drop of phenylephrine $5 \%$ was added. The lens of each eye was then re-examined with the slit-lamp and direct ophthalmoscope.

Cataract, if present, was classified into one of three stages (slight, partial, or complete) against the red glow of the fundus (Table 1).

When the severe grade of CDK was present 
Table 1 Definitions of categories of cataract

0 Normal. No opacities detected

1 Slight. Less than a third of the red glow is obscure. Details of the fundus are visible

2 Partial cataract. More than a third of the pupil area is obscure, but a partial red glow remains. Only the optic disc and main vessels are visible

3 Complete cataract. No red glow visible

The presence and degree of lens opacities were judged by viewing through a direct ophthalmoscope and against the red glow of the fundus.'

\section{Table 2 Prevalence of $C D K$}

Standardised rates (WHO's African standard population)

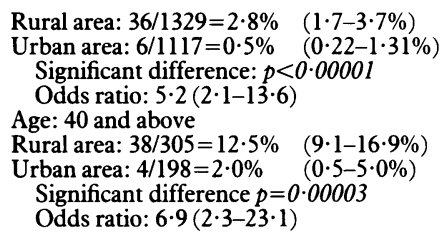

(six cases) and it was not possible to see clearly the centre of the lens with the eye looking straight ahead, the patient's gaze was directed downwards. It was then possible to examine the upper half of the lens, by looking through clear cornea over the band of keratopathy. Similarly the lower part of the pupillary area was seen with the eye turned upwards. Lastly, slight lateral or moscope allowed us to differentiate between the shadow cast by keratopathy and the lens opacities.

\section{Results}

PREVALENCE

In the rural sector the prevalence of $\mathrm{CDK}$ was five times higher than in the urban $(2 \cdot 8 \%$ vs $0.5 \%$ ) (Table 2). Moreover, the prevalence rates varied according to districts, the highest rates having been observed where inhabitants' activities were related to the sea (Table 3 ).

CASE CONTROL STUDY

Four hundred and ninety six people aged 40 and above were selected: 41 cases and 455 controls (seven aphakic patients were excluded from the study) (Table 4).

The analysis did not reveal any association between CDK and sex, but showed a marked relationship with age (Table 5).

There was a significant association between various grades of cataract and the presence of CDK, even after stratification by age (Table 6). This relationship was confirmed after matching by age, sex, and neighbourhood: opacification of the lens was about three times commoner in

Tistribution; standardised rates

\begin{tabular}{ll}
\hline District & Prevalence \\
\hline Obock & $6 \cdot 1 \%^{\star}$ \\
Ali-Sabieh & $2 \cdot 4 \%^{\star}$ \\
Tadjourah & $2 \cdot 3 \%^{\star}$ \\
Dikhil & $2 \cdot 0 \%^{\star}$ \\
Dijibouti & $1 \cdot 0 \%^{\star}$ \\
$\quad$ (rural) & Diibouti \\
$\quad$ city) & $0 \cdot 5 \%$ \\
\hline
\end{tabular}

${ }^{\star} \mathrm{p}<0.01$

Table 4 Distribution, by 10-year age classes, of CDK cases and controls vertical movements made with the ophthal-

patients with CDK than in patients without CDK (Table 7). Nevertheless, this relationship ought to be carefully interpreted, particularly because of the bias introduced by inaccurate knowledge of age, and also on account of confounders such as nutritional, socioeconomic, and occupational factors.

A strong relationship was found between CDK and exfoliation syndrome. In the case control study exfoliation syndrome was about 10 times commoner in patients with CDK (Table 8). However, the exfoliation syndrome and CDK

Table 5 Case control study. Age: 40 and above, rural+ urban areas. $N o=496(209$ males and 287 females $): 41 C D K$ (cases) and 455 controls

\begin{tabular}{lll}
\hline Sex & & \\
Males: & $18 / 209=8 \cdot 6 \%$ & \\
Females: & $23 / 287=8 \cdot 0 \%$ & \\
Age & average $=57$ years $($ SD $8 \cdot 2)$ & \\
CDK: & average $=48$ years $($ SD $8 \cdot 4)$ & \\
Controls: & Analysis of variance: $\mathrm{F}(1,501)=40, p<0 \cdot 00001$ & \\
An &
\end{tabular}

Table 6 Association between CDK and cataract; stratification by 10-year age classes

\begin{tabular}{|c|c|c|c|c|c|c|}
\hline \multirow[b]{2}{*}{ Age } & & \multirow[b]{2}{*}{ No } & \multicolumn{4}{|c|}{ Categories of cataract } \\
\hline & & & 0 & 1 & 2 & 3 \\
\hline $40-49$ & $\begin{array}{l}\text { CDK+ } \\
\text { Controls }\end{array}$ & $\begin{array}{r}4 \\
234\end{array}$ & $\begin{array}{l}50 \% \\
95 \%\end{array}$ & $\begin{array}{r}50 \% \\
3 \%\end{array}$ & $\begin{array}{l}0 \% \\
1 \%\end{array}$ & $\begin{array}{l}0 \% \\
1 \%\end{array}$ \\
\hline $50-59$ & $\begin{array}{l}\text { CDK+ } \\
\text { Controls }\end{array}$ & $\begin{array}{r}18 \\
157\end{array}$ & $\begin{array}{l}55 \% \\
71 \%\end{array}$ & $\begin{array}{r}p< \\
28 \% \\
7 \%\end{array}$ & $\begin{array}{r}0001 \\
0 \% \\
6 \%\end{array}$ & $\begin{array}{r}17 \% \\
6 \%\end{array}$ \\
\hline $60-69$ & $\begin{array}{l}\text { CDK+ } \\
\text { Controls }\end{array}$ & $\begin{array}{l}14 \\
48\end{array}$ & $\begin{array}{r}7 \% \\
42 \%\end{array}$ & $\begin{array}{r}21 \% \\
25 \% \\
\end{array}$ & $\begin{array}{l}21 \% \\
14 \%\end{array}$ & $\begin{array}{l}50 \% \\
19 \%\end{array}$ \\
\hline $70-80$ & $\begin{array}{l}\text { CDK+ } \\
\text { Controls }\end{array}$ & $\begin{array}{r}4 \\
16\end{array}$ & $\begin{array}{r}0 \% \\
31 \%\end{array}$ & $\begin{array}{l}25 \% \\
19 \%\end{array}$ & $\begin{array}{r}0 \% \\
6 \% \\
0.02\end{array}$ & $\begin{array}{l}75 \% \\
44 \%\end{array}$ \\
\hline
\end{tabular}

Age adjusted analysis of association between $\mathrm{CDK}$ and cataract (grades $1+2+3$ vs grade 0 ) by Mantel-Haenszel method: MantelHaenszel weighted odds ratio $=3 \cdot 91.95 \%$ confidence limits $=$ $1 \cdot 77-8 \cdot 63$. Mantel-Haenszel summary $\chi^{2} 10.91, p=0.0095$.

Table 7 Association between CDK and lens opacification. Matching for age, sex, and neighbourhood (lens opacities = cataract categories $1+2+3$ )

\begin{tabular}{|c|c|c|c|c|}
\hline & \multicolumn{2}{|c|}{ Lens opacities } & \multicolumn{2}{|c|}{ No lens opacities } \\
\hline & No & $\%$ & No & $\%$ \\
\hline $\begin{array}{l}\text { CDK } \\
\text { Controls }\end{array}$ & $\begin{array}{l}30 \\
43\end{array}$ & $\begin{array}{l}73 \% \\
51 \%\end{array}$ & $\begin{array}{l}11 \\
40\end{array}$ & $\begin{array}{l}27 \% \\
49 \%\end{array}$ \\
\hline
\end{tabular}

$\chi^{2}($ Yates' correction $)=4 \cdot 3, p=0 \cdot 03$. Odds ratio $=2 \cdot 6(1 \cdot 1-6 \cdot 1)$.

Table 8 Association between CDK and exfoliation syndrome $(E S)$

\begin{tabular}{lcc}
\hline & No & $\%$ with ES \\
\hline 1 Case control study: & $6 / 41$ & $14 \cdot 6 \%$ \\
CDK: & $8 / 455$ & $1 \cdot 75 \%$ \\
Controls: & \\
Fisher's exact test: $p=0 \cdot 0004$ & \\
Odds ratio=9.6 $(2 \cdot 7-32 \cdot 7)$ & \\
2 Matching for age, sex, and neighbourhood. Stratification by \\
cataract: \\
Adjusted $\chi^{2}$ (Mantel-Haenszel) $=4 \cdot 9, p=0 \cdot 026$ \\
Cataract-adjusted odds ratio for ES $=6 \cdot 4(1 \cdot 2-33 \cdot 1)$ \\
\hline
\end{tabular}

Table 9 Association between CDK and sequelae of corneal perforations; case control study

\begin{tabular}{lrcc}
\hline Age & No & CDK cases & Controls \\
\hline $40-49$ & 238 & $4(2 \%)$ & 234 \\
$50-59$ & 175 & $18(10 \%)$ & 157 \\
$60-69$ & 62 & $14(23 \%)$ & 48 \\
$70-80$ & 20 & $4(20 \%)$ & 16 \\
Total & 495 & 40 & 455 \\
\hline
\end{tabular}

\begin{tabular}{lcc}
\hline & No & $\%$ with sequels \\
\hline CDK: & $5 / 41$ & $12 \%$ \\
Controls: & $3 / 455$ & $0 \cdot 7 \%$ \\
Fisher's exact test: $p=0 \cdot 0003$ & \\
Stratification by age: & \\
Adjusted $\chi 2($ Mantel-Haenszel $)=27 \cdot 7, p<0 \cdot 00001$ \\
Age adjusted odds ratio $=31 \cdot 82(8 \cdot 8-115 \cdot 2)$
\end{tabular}


are both related to age, climatic conditions, and probably cataract. Moreover, these three factors are also interrelated among themselves and form three counfounding variables which it is necessary to control to study the true relationship between CDK and the exfoliation syndrome. After matching for age and climatic conditions, and after adjustment for cataract, a significant association between CDK and the exfoliation syndrome was still observed: the odds ratio was 6.4 , that is, the exfoliation syndrome was about six times commoner in patients with $\mathrm{CDK}$ than in controls of similar age, sex, climatic conditions, and lens status.

Even though this was not among our study objectives, while going through our data we noticed that a significant proportion $(12 \%)$ of CDK patients had been recently afflicted by a non-traumatic, widespread corneal ulceration, leading to adherent leucoma or phthisis bulbi after perforation. On the other hand, out of the 455 controls only three were seen to have this type of lesion (which represents $0.7 \%$ of the controls). Thus a highly significant association existed between CDK and ulceration: sequelae of corneal perforations were about 30 times commoner in patients with CDK than in controls of similar age (Table 9).

\section{Discussion}

The results obtained from this survey lead to a first evaluation of CDK prevalence in the Republic of Djibouti. They confirm its high level of occurrence in this part of Africa. Moreover, this is where it was described for the first time by Bartolucci in $1933 .^{6}$

In comparison with central Africa its prevalence here is higher: $2 \cdot 8 \%$ vs $1.7 \%$ in northern Chad (standardised rates). ${ }^{2}$ In fact the prevalence of CDK seems to vary according to living conditions, ranging from $6 \%$ in seaside dwellers to $0.5 \%$ in city dwellers living a short distance away and sharing the same climatic conditions. Thus what was observed in Chad over an extensive area was observed also in Djibouti, where a large city, vast stretches of desert, a coast line and high mountains all come together within a few square kilometres.

The relationship between $C D K$ and the exfoliation syndrome had already been found in Chad during a cross-sectional survery, but it was less evident in a case control study done in Somalia. ${ }^{1}$ On the contrary, the alterations of the anterior lens capsule as described by Johnson $e t$ $a l^{1}$ in Somalia were not observed anywhere in Djibouti during our survey. However, we did come across cases of herniation or lens capsule bagging among the patients of the ophthalmological department of the General Hospital of Djibouti (four out of 230 cases, that is $1 \cdot 7 \%$ ), but this was even less frequent in Chad.

As for the relationship between CDK and glaucoma, no study of it was possible owing to the small size of the sample.

Matching and adjustment techniques lead us to believe that relationships observed between $\mathrm{CDK}$ and cataract do not depend solely on age and climatic conditions. On the contrary, it appears that eyes affected by CDK should be considered as 'high-risk eyes' which need to be kept under close observation, especially with regard to glaucoma.

Finally, as for perforating ulcerations, which seem to pose a real threat to these patients, it would be useful to do some thorough research, particularly with the aetiological aspects in mind.

This work was supported by l'Organisation pour la Prévention de la Cécité, Paris; Ministère de la Coopération, Paris, France.

1 Johnson GJ, Minassian D, Franken S. Alterations of the anterior lens capsule associated with climatic keratopathy. $B$ f Ophthalmol 1989; 73: 229-34.

2 Resnikoff S. Bietti's keratopathy. A study of risk factors in central Africa. F Fr Ophtalmol 1988; 11: 733-40.

3 Taylor HR. The environment and the lens. $\mathrm{Br} \mathcal{F}$ Ophthalmo 1980; 64: 303-10.

4 Cochran WC. Sampling techniques. New York: Wiley, 1963.

5 Henderson $\mathbf{R H}$, Sundaresan T. Cluster sampling to assess immunization coverage: a review of experience with simplified sampling method. Bull WHO 1982; 60: 253-60.

6 Fretillere Y, Vedy J, Chovet M. A propos de 114 cas de dystrophie coréenne de Bietti observés en Côte Française des Somalis. Med Trop (Mars) 1967; 27: 293-302. 